\title{
Integration of Supply Chain Management Using Multiagent System \& Negotiation Model
}

\author{
Amit Kumar Goel ${ }^{1}$, S. L. Gupta ${ }^{1}$, S. Srinivasan ${ }^{2}$, and B. K. Jha ${ }^{3}$
}

\begin{abstract}
Supply chain consists various components/ identities like supplier, manufacturer, factories, warehouses, distributions agents etc. These identities are involved for supplying raw materials, components which reassembles in factory to produce a finished product. Multiagent systems (MAS) offer new perspectives compared to conventional, centrally organized architectures in the scope of supply chain. Conventional SCM systems are often restricted in terms of dynamic behavior. This paper focuses on an ongoing effort in the development of MAS for supply chain management .In our frame work we studies about the negotiation among the different related components of supply chain. In real world these role of individual component can be implemented through distinct agent. But it is not possible to describe the function and procedures for all software agents in an uncertain E-Commerce like traditional supply chain system. When an order arrives, a virtual supply chain may emerge from the system through automated or semi-automated negotiation processes. The proposed system can remove the problem of communication \& decision making for negotiating system for supply chain.
\end{abstract}

\section{Index Terms - MAS, SCM, Negotiation}

\section{INTRODUCTION}

Automobile industries shift from a traditional local business model to a global one, OEM's \& suppliers.

Automotive players are in various stages of transformation from a localized "buy/make/sell" model to global "buy/move/make/move/sell anywhere" model. Companies must maintain or enhance supply chain flexibility \& customer responsiveness despite these major shifts in automobile industry. Now the companies cannot base on their sourcing decisions solely on traditional matrices. They will have to consider additional supply chain factors such as inbound lead times $\&$ associated variability, supply chain risk, protection of supply $\&$ logistics costs as well as risk $\&$ inventory costs. Failure to do so could result in increased cost. MAS perfectly suit these demands for global flexibility, co-operation and, at the same time, local autonomy. The individual projects that are involved in the research activities presented in this paper address these problems and offer services in the range of SCM scheduling (NegE [1], shop floor production planning and control (KRASH[2], IntaPS [3] and FABMAS [4] ) and proactive tracking and tracing services (ATT/SCC[5]) to guarantee the reliability of supply chain processes in the case of unforeseen disruptions.

Manuscript received December18, 2010; revised April 4, 2011.

${ }^{1}$ Research Scholar BIT Mesra - Professor Department of ManagementBIT Noida.

${ }^{2}$ Professor Department of Computer Science-PDM Badhurgarh.

${ }^{3}$ Professor Department of Management-BIT Noida.

\section{SCM ARCHITECTURE}

The reference model comprises a simplified supply chain of a manufacturer of automobile company. Its main value creation is due to the assembly of parts that it process from different suppliers.

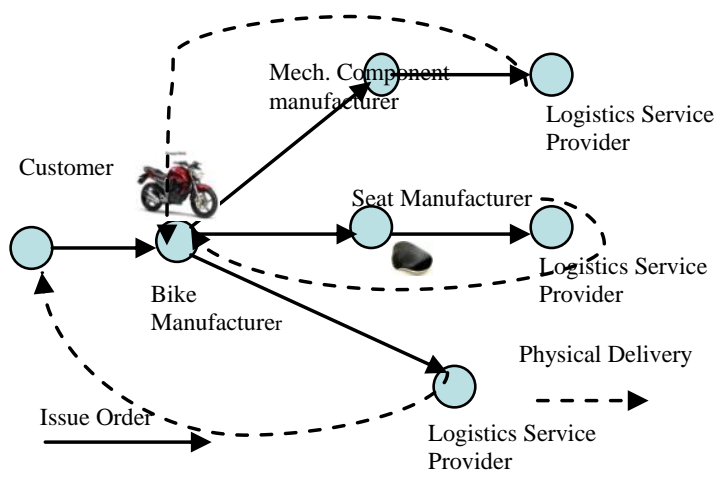

Figure 1: Supply chain scenario

In our scenario a manufacturer of mechanical components (like gear, silencer, lights etc.) and a supplier of seats are incorporated. The logistics service provider those are responsible for delivering the parts to the producer and to its customers are integrated in the figure. The complexity of managing supply chains results in many different independent tasks such as the planning, execution and control li ng of production, transportation and warehouse process. So multiple MAS specializing on certain tasks have to interact. The basic scenario focuses on production processes; where as aspects of transportation can be integrated. Table 1 gives an overview on the various functionality of each MAS involved.

TABLE 1: OVERVIEW OF M AS FUNCTIONALITY

\begin{tabular}{|l|l|}
\hline M ain Functionality & Agent \\
\hline Negotiations between enterprises & NegE \\
\hline $\begin{array}{l}\text { Integrated Process Planning \& } \\
\text { Scheduling }\end{array}$ & IntaPS \\
\hline $\begin{array}{l}\text { Production Planning and } \\
\text { Controlling (focus on Assembly } \\
\text { industries) }\end{array}$ & K RASH \\
\hline $\begin{array}{l}\text { Production Planning and } \\
\text { controlling (focus on batch } \\
\text { production) }\end{array}$ & FABM AS \\
\hline $\begin{array}{l}\text { Operational tracking of orders } \\
\text { including suborders in supply } \\
\text { chain }\end{array}$ & ATT \\
\hline $\begin{array}{l}\text { Analysis of historical tracking } \\
\text { information (tracing) }\end{array}$ & SCC \\
\hline
\end{tabular}


A logical starting point for a typical supply chain management cycle is the distributed global planning of supply chain activities. This is achieved with NegE system. After generating an initial plan of orders and suborders concerning prices and time points of delivery, software agents located at the different supply chain partners carry on negotiations. Thereby they optimize the cost s and the due dates of deliveries.

\section{A MULTI-AGENT FRAMEWORK FOR DYNAMIC SUPPLY CHAIN FORMATION}

In this work, supply chain formation is modeled as an agent-mediated decision making and coordination problem. As shown in Fig. 2, a society of software agents, including a Service Requester, and a set of Service Brokers and Service Providers, is proposed. This corresponds to a supply chain, where a product service is fulfilled through a set of services including procuring components, preprocessing components, assembling components into products, post-processing products, and delivering components or products whenever the customer and service providers are distributed in different locations. For clarification, we use component service to indicate an individual service involved in the chain, and composite service to indicate an integrated service achieved through the supply chain. With regard to a service request, the issues of time, cost, and location are considered important attributes of quality of service (Menasce,2004). Normally, a composite service should be completed on or before the due date and delivered to the location required by the customer; a feasible solution with the lowest cost will be accepted by the customer. Each component service should be scheduled to start after its preceding service is completed before its succeeding service starts. For clarity, we only consider the situations where there is only one preceding and succeeding service of a component service in this paper. Moreover, when the customer and component service providers are distributed in different locations, one or more delivery services are required to be embedded into the service chain. As discussed, we face both ambiguity in determining the requirements of component services and uncertainties of solutions to component services, which may further result in dynamics and difficulties in searching, selecting, and coordinating the solutions through out the formation process. A major challenge of this work is that available resources of the component services (including service providers and their solutions) are unknown in advance. To find them, we need to send out service requests to service providers. However, we only have the constraints of the composite service and not the constraints of the component services. To solve the problem, we may first estimate the constraints of each component service and then refine this estimate based on real-time responses from service providers and real-time coordination among the services (Wangetal., 2008). Upon receiving a request (e.g.,1000 products to XYZ gears before25-02-2010)from a customer, the Service Requester will decompose the customer's request into a set of services with estimated constraints for each component service. The estimation is based on the customer's request as well as the history information of the component services. In this example, the estimation of time constraints is based on the average percentage of time spent on the services. The start time of the first service and the due time of the last service are taken as fixed, as required by the customer. Moreover, each service takes place in alocation, and its output can be transported to another place (destination) for a succeeding service when necessary. The cost issue is considered in selecting cheaper partial solutions from providers; the total cost required by the customer will be considered at the final stage when combining the partial solutions toward a global solution. Associated with the supply chain, a set of Service Brokers and Service Providers is deployed, each for a specific component service. To decrease the complexity of the coordination process caused by adding delivery services on demand, we treated delivery as a type of standard service that could be provided by a certain global delivery company (e.g.,DHL), and could be bound with any component service when necessary. After receiving service requests from the Service Requester, Service Brokers will send them to Service Providers for collecting suitable solutions to each service. However, available solutions may be incompatible to form a global solution. A Service Broker needs to coordinate with its neighboring brokers to adjust the service requirements for seeking new bids that may reach a global solution.

\section{MULTI-AGENT NEGOTIATION AND DECISION MAKING FOR DYNAMIC SUPPLY CHAIN FORMATION:}

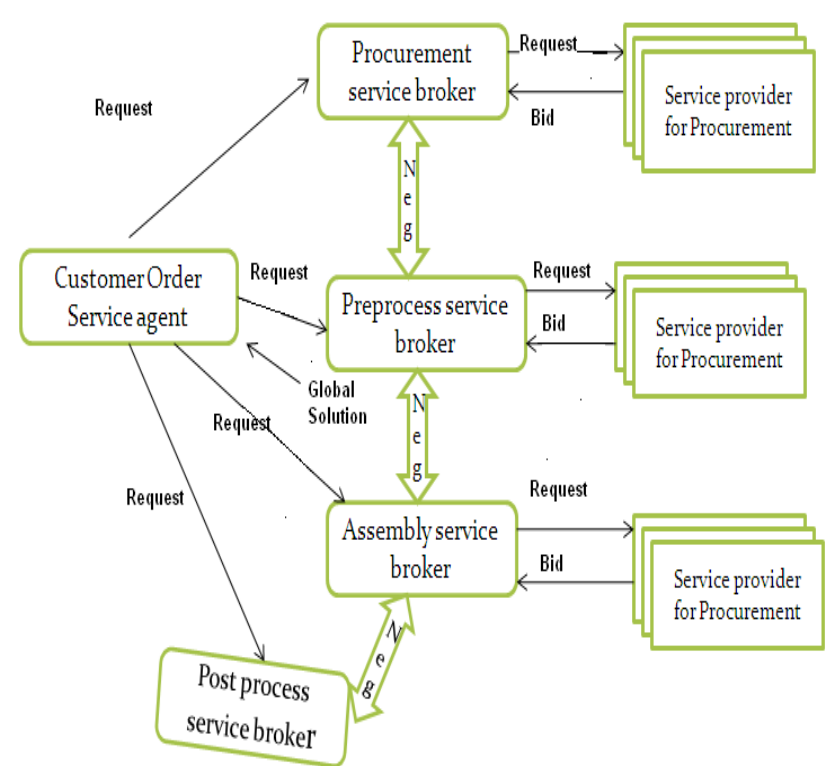

Figure 2: A multi-agent framework of -supply chain formation

In an argumentation-based multi-agent negotiation and decision making system, the agent should be equipped with the mechanisms to do the following: exchange information with other agents to update their understanding of the social situation; generate outgoing arguments to help other agents further under-stand the preferences and conflicts to improve the negotiation process; and at the same time respond to incoming arguments to update and adjust its own decision making process. In this study, the essential activities of Service Broker agents involved in the negotiation and decision making for supply chain formation are elaborated as follows. 


\section{A. Generating and exchanging partial solutions}

After receiving a service request from the Service Requester, each Service Broker may forward the request to corresponding Service Providers for collecting solutions, i.e., bids for the services. In order to reach a mutually accepted global solution, the agents need to exchange relevant information for negotiation and coordination. The information exchange should be minimized to consider communication cost, privacy policies, and system robustness. In this example, each Service Broker exchanges the information regarding the solutions to its own services with its neighboring Service Brokers.

We use Si to denote a component service, and Rqi to denote the requirement of the service. $\mathrm{Rq}_{\mathrm{i}}$ is defined as follows:

We use Si to denote a component service

$\mathrm{Rq}_{\mathrm{i}}=\left[\mathrm{sti}_{\mathrm{i}}, \mathrm{et}_{\mathrm{i}}, \mathrm{cost}_{\mathrm{i}}\right] \mathrm{sti}-\mathrm{start}$ time

eti - denote $s$ due time for $\mathrm{S}_{\mathrm{i}}$

costi - denotes expected cost of $\mathrm{Si}_{\mathrm{i}}$

Bid is re garded as a solution to a component service

$\mathrm{Bid}_{\mathrm{ij}}=\left[\mathrm{b} \_\mathrm{d}_{\mathrm{ij}}, \mathrm{s} \_\mathrm{t} \mathrm{tij}, \mathrm{e} \_\mathrm{t} \mathrm{ij}, \mathrm{cij}, \mathrm{loc}_{\mathrm{ij}}, \mathrm{des} \mathrm{ij}\right]$

$\mathrm{c}_{\mathrm{ij}}$ - cost claime $\mathrm{d}$ by $\mathrm{t}$ he service provider

$\operatorname{loc}_{\mathrm{ij}}$ - location of the service

$\operatorname{des}_{\mathrm{ij}}$ - destination of the service.

B. Filtration of bids by service broker provided by service provider.

A newly received ${ }_{\text {bidi } \alpha}$ (bid $\alpha$ for service i) is identified as a dominated bid if it is not cheaper and more time saving than an existing candidate solution $\mathrm{Bid}_{\mathrm{ij}}$ by satisfying condition.

$\mathrm{C}_{\mathrm{i} \alpha} \geq \mathrm{C}_{\mathrm{ij}}$ AND s_ti $\leq \leq \mathrm{s} \_\mathrm{tij}$ AND e_t $\mathrm{t} \alpha \geq \mathrm{e}_{-} \mathrm{t}_{\mathrm{ij}}$ AND loci $\alpha=\operatorname{loc}_{\mathrm{ij}}$ AND desi $\alpha=\operatorname{des} \mathrm{ij}$

Any existing solution $\mathrm{Bid}_{\mathrm{ij}}$ will be dominated by new bid $i \alpha$ if the new bid is cheaper and more time-saving than the existing on e by satisfying the following condition.

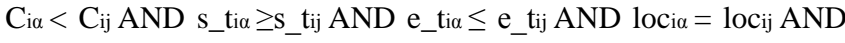
desi $=$ desij

\section{FIGURING OUT MUTUALLY COMPATIBLE SOLUTION:}

After receiving the bids from its neighboring Service Brokers, each broker will evaluate these bids and identifying some of its own solution that are compatible with the solution of its neighbors. We denote service $u$ and service $\mathrm{v}$ as the preceding and succeeding service of service $i$, and $B^{i} \operatorname{di\alpha } B^{i} d u \beta B^{i} d v \gamma$ as bids of service $i, u$ and $v$ respectively. If the two bids are compatible by satisfying the following condition:

$$
\text { s_ti } \alpha>\text { e_tu } \beta \text { AND loci } \alpha=\operatorname{desu} \beta
$$

The service broker will al so link $\mathrm{B}^{\mathrm{i}} \mathrm{di \alpha}$ ( a bid of its own service) with $B^{i} d v \gamma$ ( a bid of its succeeding service) if the two bids are compatible by satisfying the following condition

$$
\text { e_ti } \alpha>\text { s_t } v \gamma \text { AND desi } \alpha=\operatorname{loc}_{v \gamma}
$$

If the provider cannot make the service output reach the location of the succeeding service, a standard delivery service (e.g., DHL) could be bound to the service with delivery cost and delivery time taken into account.

Each bid is posted with its start time, end time, and cost; the mutually compatible solutions are indicated by the connections among them. The end time and cost of the solutions have been adjusted when a delivery service is needed for transporting the output of a service to its succeeding service. The connection between the solutions will be removed if the conditions are violated (e.g., the cost is greatly increased, or the due time is delayed later than the start time of the succeeding service) after the adjustment by adding a delivery service.

\section{SUMMARY}

A MAS based SCM approach is presented. It addresses the architectural, the planning and the execution aspects of supply chain management. Besides the functional requirements like an integrated SCM scheduling, non functional requirements like an integrated SCM scheduling, reliability and the flexibility of the system are also met.

Supply chain formation is a complex task that requires the ability to search, schedule, and coordinate a set of services from a large number of service resources under various constraints and uncertainties. Decision making and coordination in supply chain formation is usually unstructured and partitioned into sub-problems, and software agents have become a key enabling technology for automated negotiation and decision making in this area. Existing approaches have been limited by concentrating on the situations where the requirements of each component service are determined and relevant resources and their status are known in advance. They have relied on complete information regarding service requirement and resources without adequately dealing with the dynamisms and uncertainties of the environments (Wang et al., 2008).This study aims to support supply chain partners with a feasible solution for achieving coherence in a collaboration plan. We have proposed an approach to automate the supply chain formation in dynamic and uncertain environments, through agent-mediated negotiation and decision making. For clear presentation and ease of understanding, the paper has focused on the mechanism of automatic decision making and negotiation among software agents in service composition. Each agent works as a broker for each service type, dedicated to selecting solutions for each component service as well as interacting with other agents in refining the decision making to achieve compatibility. Finding a global solution to service composition requires that all agents coordinate and find the solutions that satisfy not only their own constraints, but also inter-agent constraints derived from interdependencies among services in a business process. Due to their irregular and ill-structured nature, systems for such collaborative problems may integrate the users into the problem-solving processes. This system can be viewed as an assistant, where managers of business entities interact with the system to confirm or modify the requests and the solutions proposed by the system. Human-based processes have historically had to deal with the complexity and need for flexibility, adaptability and spontaneity in the absence of comprehensive technological support. There are 
opportunities to learn from these dynamics in virtual teams in the quest for better technological support (Qureshi and Vogel, 2004; Rutkowski et al., 2002).

\section{REFERENCES}

[1] DISPOWEB project, "Dispositive supply-Web-Coordination", [Internet], Available from: http://www.dispoweb.de/ [Accessed 13.3.03].

[2] KRASH project, "Karlsruhe Robust Agent Shell”,[Internet] Available from http://www.ipd.uka.de/KRASH/[Accessed 13.3.03].

[3] IntaPS project “, Integrated Agent based Process planning and production Control," [Internet] Available from: http://www.intaps.org[Accessed 13.3.03]

[4] ATT/SCC project, "Agent-based tracking and Tracing of Business Processes", [Internet], Available from http://www.wi2.uni -erlangen.de/research/ATT/i ndex-e.html [Accessed 13.3.03]

[5] Baumgaertel, H., John, H., 2003. Combining agent-based supply net simulation and constraint technology for highly efficient simulation of supply networks using APS systems. Proceedings of the 2003 Winter Simulation Conference. Bench-Capon, T.J.M., Dunne, P.E., 2007. Argumentation in artificial intelligence. Artificial Intelligence 171 (10-15), 619-641.

[6] Caridi, M., Cavalieri, S., 2004. Multi-agent systems in production planning and control: an overview. Knowledge Information Systems 15 (2), 106-118.

[7] Chiu, D.K.W., Yueh, Y.T.F., Leung, H.-f., Hung, P.C.K., 2008. Towards ubiquitous tourist service coordination and process integration: a collaborative travel agent system with semantic web services. Information Systems Frontier, 10.1007/s10796-008-9087-2.

[8] Christiaanse, E., Kumar, K., 2000. ICT-enabled coordination of dynamic supply webs. International Journal of Physical Distribution \& Logistics Management 30 (3/4), 268- 285.

[9] Eder, J., Panagos, E., Rabinovich, M., 1999. Time constraints in workflow systems, In: 11th International Conference on Advanced Information Systems Engineering (CAiSE), LNCS, 1626, 286-300.
[10] Epstein,J.L., 2001. Predicate Logic: The Semantic Foundations of Logic. Wadsworth Thomson Learning, Belmont, CA.Faratin, P., Sierra, C., Jennings, N.R., 1998. Negotiation decision functions for autonomous agents. International Journal of Robotics and Autonomous Systems 24 (3-4), 159-1 82.

[11] Fatima, S., Wooldridge, M., Jennings, N.R., 2004. An agenda based framework for multi-issues negotiation. Artificial IntelligenceJournal $152(1), 1-45$

[12] Forget, P., D’Amours, S., Frayret,J.M., Gaudreault,J., 2008. Design of multi-behavior agents for supply chain planning: an application to the lumber industry. In: Kordic, V. (Ed.), Supply Chain, Theory and Applications. I-Tech Education and Publishing, Vienna, Austria, pp. 558-568.

[13] Fox, M.S., Barbuceanu, M., Teigen, R., 2000. Agent-oriented supply-chain management. International Journal of Flexible Manufacturing Systems 12 (2/3), 165-188.

[14] Kaplan, S., Sawhney, M., 2000. E-hubs: the new B2B market-places. Harvard Business Review 78 (3), 97-1 00.

[15] Karageorgos, A., Mehandjiev, N., Weichhart, G., Ha mmerle, A., 2003. Agent-based optimisation of logistics and production planning. Engineering Applications of Artificial Intelligence 16 (4), 335-348.

[16] Kraus, S., 2001. Strategic Negotiation in Multi-Agent Environments. MIT Press, Cambridge, MA.Kraus, S., Sycara, K., Evenchik, A., 1998. Reaching agreements through argumentation: a logical model and implementation. Artificial Intelligence 104 (1-2), 1-69.

[17] Kumar, K., 2001. Technology for supporting supply chain management: introduction. Communications of the ACM 44 (6), $58-61$.

[18] Kumar, K., Becerra-Fernandez, I., 2007. Interaction technology: speech act based information technology support for building collaborative relationships and trust. Decision Support Systems 43 (2), 584-606.

[19] Laasri, B., Laasri, H., Lander, S., Lesser, V., 1992. A generic model for intelligent negotiating agents. International Journal of Intelligent and Cooperative Information Systems 1, $291-317$.

[20] Labarthe, O., Espinasse, B., Ferrarini, A., Montreuil, B., 2007. Toward a methodological framework for agent-based modelling and simulation of supply chains in a mass customization context. Simulation Modelling Practice and Theory 15 (2), 113-136. 